\title{
Spontaneous Pulmonary Hernia: A Case Report
}

\author{
Pablo Edgardo Gómez PT, Sebastián Ferreiro MD, Soledad M Esteban PT, \\ Rodrigo Fodor PT, Marcelo E Palavecino PT, and Fernando G Rios MD
}

\begin{abstract}
Hernia is defined as the protrusion of a totally or partially displaced organ from its normal visceral cavity. Most hernias occur at the level of the abdominal wall, because of a muscular defect. Pulmonary hernias are extremely rare and can be congenital or acquired. We present a 64-year-old patient who developed a spontaneous pulmonary hernia after a severe coughing episode. We describe the clinical features, diagnosis, and successful treatment. Key words: spontaneous pulmonary hernia; coughing access; surgical correction. [Respir Care 2013;58(10):e119-e122. (C) 2013 Daedalus Enterprises]
\end{abstract}

\section{Introduction}

Pulmonary hernia (or pneumocele) is a protrusion of the lung beyond the normal limits of the thoracic cavity, because of a defect in the thoracic wall. Pulmonary hernias are of extremely infrequent occurrence. Usually, they are secondary to a traumatic event or a surgical procedure; as such, spontaneous pulmonary hernias (SPHs) are scarcely mentioned in the literature. Pulmonary hernias were first described by Roland, in $1499 .{ }^{1}$ More than 3 centuries later appeared the description by Morel-Lavellee,${ }^{2}$ who classified pulmonary hernias, taking into account 2 criteria: the anatomic location (cervical, thoracic, or diaphragmatic), and the etiology (congenital or acquired). He further differentiated the acquired hernias as traumatic, pathologic, or spontaneous.

\section{Case Report}

The patient was male, age 64, with a history of COPD and arterial hypertension. He developed incremental and persistent cough during the week preceding his admission.

\footnotetext{
The authors are affiliated with the Intensive Care Unit, Sanatorio Juncal, Témperley, Buenos Aires, Argentina.

The authors have disclosed no conflicts of interest.

Correspondence: Pablo Edgardo Gómez PT, Intensive Care Unit, Sanatorio Juncal, 2779 Avenida Almirante Brown Témperley, Buenos Aires 1834; Argentina. E-mail: gomezpablorena@hotmail.com.
}

DOI: $10.4187 /$ respcare.02125
Upon experiencing dyspnea and right sided thoracic chest pain, he was brought to the emergency department.

We verified the presence of a collaborative and conscious patient. He experienced shortness of breath and some severe coughing episodes during his evaluation; hemoptoic expectoration was observed once. His vital signs were: heart rate 110 beats/min, breathing frequency 26 breaths/min, arterial blood pressure $150 / 80 \mathrm{~mm} \mathrm{Hg}$, axillary temperature $38^{\circ} \mathrm{C}$, and $\mathrm{S}_{\mathrm{pO}_{2}} 92 \%$ breathing ambient air. In the right thoracic and lumbar area we found an extensive ecchymosis. This hematoma was accompanied by swelling at the sixth intercostal space when coughing or with Valsalva maneuvers. Lung auscultation revealed signs of prolonged expiratory time, and no murmurs.

An x-ray of the thorax (Fig. 1) showed no alterations, but a computed tomogram (CT) evidenced a herniation of the right pulmonary parenchyma (Fig. 2). There was no rib fracture or evidence of callus formation in either exam. There was no pulmonary infiltrate to suggest pneumonia.

The laboratory results were: hematocrit $36 \%$, leukocytes 18,000 cells $/ \mathrm{mL}$, platelets 216,000 cells $/ \mathrm{mL}$, glucose $79 \mathrm{mg} / \mathrm{dL}$, urea $39 \mathrm{mg} / \mathrm{dL}$, sodium $137 \mathrm{mEq} / \mathrm{L}$, potassium $5.0 \mathrm{mEq} / \mathrm{L}$, chloride $104 \mathrm{mEq} / \mathrm{L}$, prothrombin $91 \%$, and kaolin partial-thromboplastin time $28 \mathrm{~s}$. The arterial blood gasometry (under room air) was: $\mathrm{pH} 7.43, \mathrm{P}_{\mathrm{aCO}}$ $34.1 \mathrm{~mm} \mathrm{Hg}, \mathrm{P}_{\mathrm{aO}_{2}} 68 \mathrm{~mm} \mathrm{Hg}$, base excess $0.2 \mathrm{mEq} / \mathrm{L}$, bicarbonate $23 \mathrm{~mm} \mathrm{Hg}$, and $\mathrm{S}_{\mathrm{aO}_{2}} 92 \%$, so oxygen therapy was not initially indicated.

He was admitted to the ICU and treatments were begun. Finding criteria of severe COPD exacerbation, antibiotics (levofloxacin), systemic corticosteroids, and inhaled bronchodilator were started. With respect to the pulmonary 


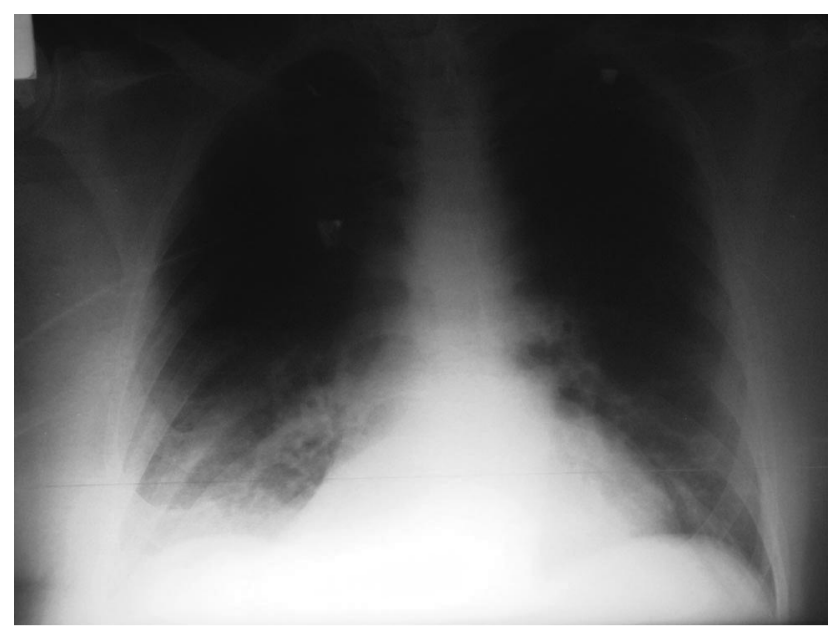

Fig. 1. Chest x-ray on admission.

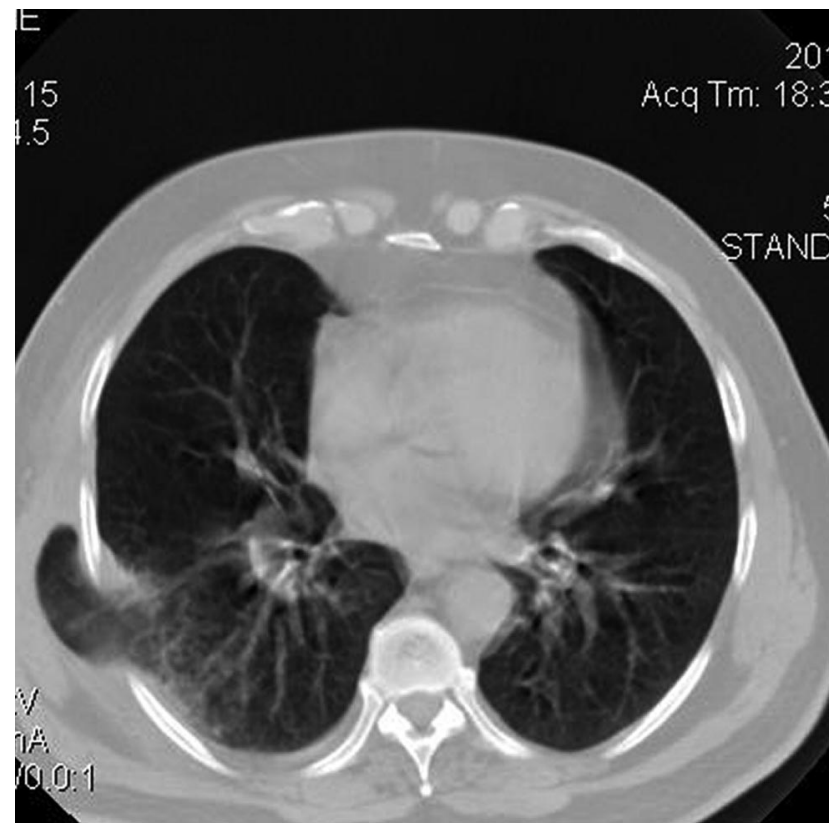

Fig. 2. Computed tomogram shows a pulmonary protrusion in the right posterolateral region.

hernia, control of coughing and containment with bandages were the initial approach. During the first 2 days he experienced partial improvement of respiratory status. Spirometry showed a very severe obstructive defect and a low FVC (related to air entrapment).

On the fourth day after hospital admission he developed fever again. His condition appeared to worsen, with dyspnea and tachypnea, poor ventilatory dynamics, and $\mathrm{S}_{\mathrm{pO}_{2}} 85 \%$ breathing room air. We added oxygen and changed antimicrobial therapy to piperacillin plus tazobactam, attending eventual nosocomial bacteria other than the initial pathogens treated. A new CT scan revealed increased pulmonary herniation, with probable incarcera-

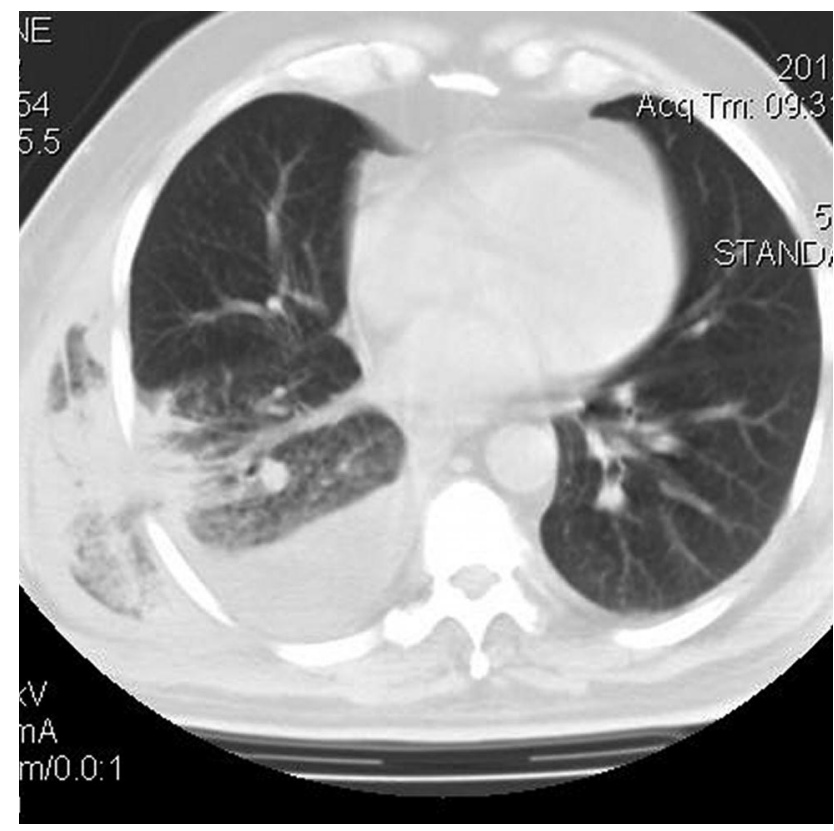

Fig. 3. Computed tomogram shows herniated lung, infiltrates in the pulmonary parenchyma, and right pleural effusion.

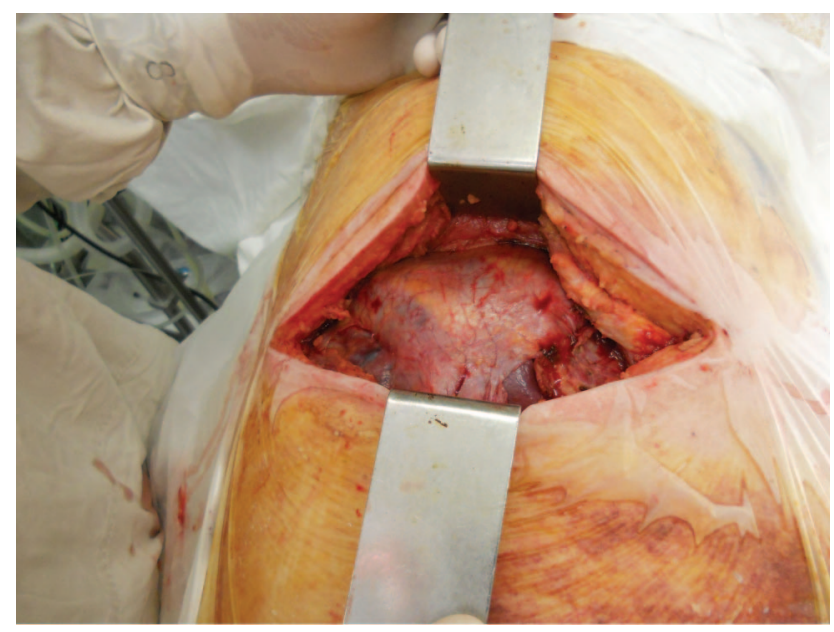

Fig. 4. Intraoperative photograph shows the sac containing the herniation.

tion of the parenchyma (Fig. 3), some infiltrates in the compromised lung (in the herniated and the adjacent lung), and right pleural effusion. He improved with medication, and surgical repair was decided upon.

A right posterolateral thoracotomy was made, and the latissimus dorsi muscle dissected. After mobilizing the serratus anterior muscle, the sac containing the herniation was exposed, located above the 6th intercostal space (Fig. 4). The thoracic surgeons found no rib fractures. The sac was opened, and protrusion of the right inferior lobe was noted, with no visible damage to the lung parenchyma. The lung was replaced into the thorax, a chest tube 


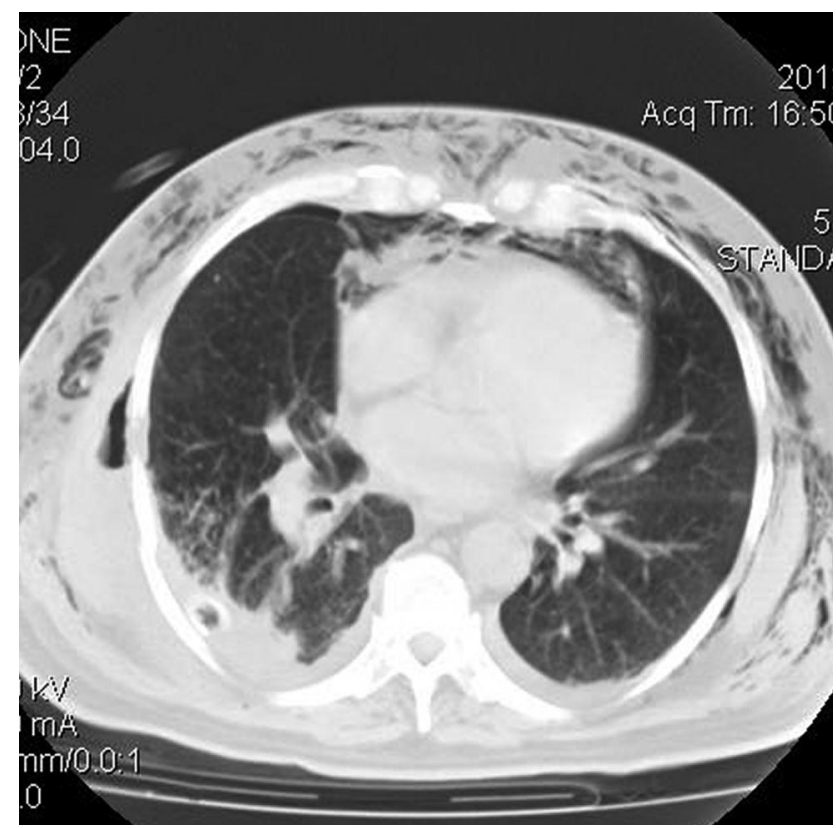

Fig. 5. Postoperative computed tomogram.

was inserted, and the intercostal space was narrowed with nonabsorbable surgical sutures, finally covering the defect with a polypropylene mesh.

The thoracic wall was repaired, but the patient developed an extrathoracic hematoma, extensive subcutaneous emphysema, and pneumomediastinum after surgery, perhaps as a result of pleural laceration (Fig. 5). Several days after the procedure these complications resolved favorably. He was released from the ICU 7 days after surgery. He was without relapse or complications at 6 months after surgical repair (Fig. 6).

\section{Discussion}

SPH due to coughing is related to a combination of 2 processes: weakness of the boundaries of the thoracic cavity, and increased intrathoracic pressure. ${ }^{3-5}$ In our patient, weakness in the intercostal muscles may have been a consequence of the systemic effect of COPD, the anatomy of the intercostal spaces, and previous use of corticosteroid.

With respect to the anatomy of the intercostal spaces, there are 3 muscles that cover its extension: the external, the medial, and the internal intercostal muscle (disposed from the surface to the deep layer). Their incomplete distribution within the spaces leads to areas of potential weakness. The anterior edge of the space (adjacent to the sternum bone) and the posterior edge (adjacent to the vertebral spine) are areas of vulnerability because they are covered by only one of those 3 muscles. ${ }^{6}$ This anatomic condition

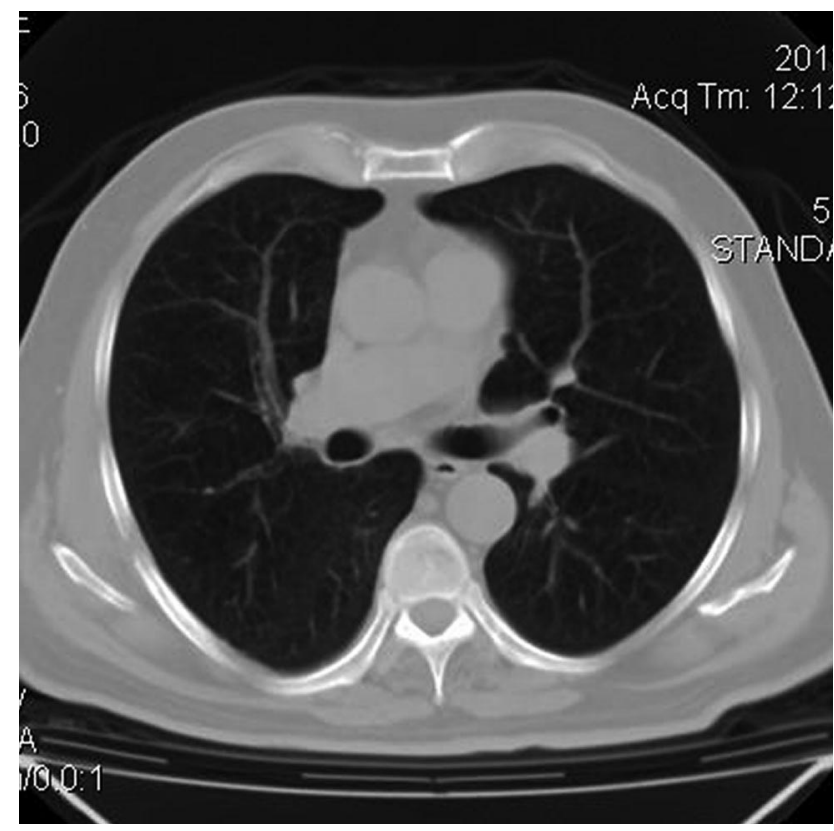

Fig. 6. Computed tomogram at 6 months after surgical repair.

could worsen in the presence of the above-mentioned situations, as COPD, air trapping (with its changes in thoracic volumes), and intrinsic muscle dysfunction because of systemic or pharmacologic issues.

The increase in intrathoracic pressure produced by a severe cough episode may generate a tear in the intercostal muscles. Although the majority of SPHs are produced in the parasternal region (anterior extreme of intercostal space), ${ }^{7,8}$ in our patient the hernia was in the posterolateral region. As mentioned above, both sites are vulnerable to SPH. Posterior SPH occurs because both the medial and internal intercostal muscles do not extend up to this limit of the space. Nevertheless, some patients develop SPH in a posterolateral situation, as the paravertebral muscles may give particular resistance in the extreme posterior edge of the intercostal space. ${ }^{7}$

The diagnosis is achieved by examination and thoracic imaging. Despite a negative x-ray result, a CT may be useful to confirm the diagnosis and determine the size and exact location. In our patient, the physical exam and CT were both useful for diagnosis and localization of the SPH.

The treatment of SPH is controversial. Nonsurgical management (cough medication and bandaging) is encouraged in asymptomatic patients and those with less extensive lesions. Surgery is indicated in patients who have intense pain or a strangulation that generates recurrent infection, hemoptysis, or respiratory status deterioration. Patients whose activity involves heavy exertion may also be considered.9-11 Our patient opted for surgery because of persistent pain, hypoxia, and re-infection. After the pericostal 
suturing and placement of prosthetic material, the patient was without relapse at a 6-month follow-up.

In summary, we determined that our patient developed a spontaneous posterolateral lung hernia as a result of vigorous coughing in a setting of COPD, a painful bulge, and ecchymosis, without rib fracture. The CT helped to delineate the size and location of the hernia. Surgical intervention was undertaken due to persistent pain, hypoxemia, signs of infection, and probable incarceration of the pulmonary parenchyma.

SPH should be considered in patients with SPH risk factors. They should be treated for the conditions that generate severe coughing-a symptom not always taken into account as a potential cause of morbidity. Surgery should be considered in symptomatic patients and in those with severe complications.

\section{ACKNOWLEDGMENTS}

We thank Andrés Civitarese MD, Sebastián Gandolfo MD, and Ezequiel Muino MD for their collaboration in this case report, and Donald F Haggerty MD, a retired career investigator and native English speaker, for translating the manuscript into English.

\section{REFERENCES}

1. Roland. De volmonis sanaripot. In: de Chavliae G, editor. Cyrugia. Liber III (cap) XXV; 1499:144.

2. Morel-Lavallee A. Hernies du poumon. Bull Mem Soc Chir Paris 1845;1:75-195. Article in French.

3. Munnell ER. Herniation of the lung. Ann Thorac Surg 1968;5(3): 204-212.

4. Weissberg D, Refaely Y. Hernia of the lung. Ann Thorac Surg 2002;74(6):1963-1966.

5. Donato AT, Hipona FA, Navani S. Spontaneous lung hernia. Chest 1973;64(2):254-256

6. Forty J, Wells FC. Traumatic intercostal pulmonary hernia. Ann Thorac Surg 1990;49(4):670-671.

7. Bhalla M, Leitman BS, Forcade C, Stern E, Naidich DP, McCauley DI. Lung hernia: radiographic features. AJR Am J Roentgenol 1990; 154(1):51-53.

8. Brock MV, Heitmiller RF. Spontaneous anterior thoracic lung hernias. J Thorac Cardiovasc Surg 2000;119(5):1046-1047.

9. Sulaiman A, Cottin V, De Souza Neto EP, Orsini A, Cordier JF, Gamondes JP, et al. Cough-induced intercostal lung herniation requiring surgery: report of a case. Surg Today 2006;36(11):978-980.

10. Kaliyadan A, Kebede A, Ali T, Karchevsky M, Vasseur B, Patel N. Spontaneous transient lateral thoracic lung herniation resulting in systemic inflammatory response syndrome (SIRS) and subsequent contralateral lung injury. Clin Med Insights Case Rep 2011;4:39-42.

11. Jastrow KM, Chu D, Jaroszewski D, Huh J, Bakaeen F. Posterior lung herniation after a coughing spell: a case report. Cases J 2009; 2(1):86. 